\title{
Caspar David Friedrich e Edward Hopper: a melancolia na relação entre homem e natureza
}

Raphael Fonseca

\section{Resumo}

O presente texto visa fazer uma aproximação entre as poéticas dos pintores Caspar David Friedrich e Edward Hopper, pelo viés da temática da melancolia dada na relação entre homem e natureza. Para tal, se fez necessário a comparação iconográfica e cultural entre algumas de suas obras, tendo em vista seus diferentes contextos histórico-artísticos e depoimentos.

Palavras-chave: Friedrich, Caspar David (1774-1840); Hopper, Edward (1882-1967); melancolia; paisagem.

\section{Abstract}

This article makes an approach between the poetics of the painters Caspar David Friedrich andEdwardHopperthrough thethemeofmelancholyin therelation between man and nature. To reach this, it was necessary to compare iconographically and culturally some of their artworks, having in mind the different historical artistic contexts and testimonies.

Keywords: Friedrich, Caspar David (1774-1840); Hopper, Edward (1882-1967); melancholy; landscape.

Uma pintura (fig. 1). Uma paisagem, algumas figuras. Um horizonte bem definido, perfurando os três humanos que se encontram ao centro da composição. O céu é amplo e seu espaço na pintura inclusive é maior do que o dedicado às rochas em que as figuras estão sentadas. Percebe-se uma movimentação das nuvens; elas fazem dois movimentos curvos. Um de tons escuros e mais próximo do luar que se apresenta ao fundo da composição, o ponto de fuga. O outro sobre as três figuras, de tons mais claros, contrastando com as outras nuvens, criando uma elipse que coroa a lua nascente. Esse momento de transição, por sua vez, tem de fundo uma iluminação de tons claros, vermelhos, quase dourados, o resquício da tarde. Em seu lugar entrará uma noite aparentemente nebulosa, 
nublada, de tons sóbrios. O mar se estende timidamente até o encontro de alguma coisa que não conseguimos alcançar, nos deixando a impressão de ir até e, quem sabe para além, da lua que se anuncia. Dois barcos contribuem com a idéia de profundidade da pintura, estando um iluminado já pelo brilhante astro e o outro ainda a caminho dessa luz (ou talvez não e esteja a caminho das rochas), contrastando com as pequenas insinuações de ondas que o mar apresenta.

As rochas. Tons que giram em torno do marrom e do vermelho-tijolo, contrastando com o céu azul-esverdeado e violeta. Uma construção imagética que cresce, ascende e se inicia com pequenas rochas mais à parte de baixo da pintura até chegar ao seu ápice, a grande rocha em que as figuras humanas estão sentadas e de costas para o observador. As cores de suas roupas de alguma forma se confundem com as cores da própria paisagem; a figura da direita parece ser um desdobramento das rochas, as outras duas parecem ser partes do mar e do céu transformados em humanos, com exceção apenas da saia vermelha que se destaca sutilmente da composição como um todo, ainda a se relacionar com algumas pedras que se encontram na mesma direção, mais abaixo. A luz da lua incide sobre suas faces. Mesmo se tratando de mais de uma figura, não são enxergadas isoladamente; é como se elas lá estivessem apenas para representar o homem em geral. Elas têm leveza, são bem trabalhadas plasticamente em relação às suas pequenas individualidades, mas ao mesmo tempo parecem ser uma coisa só. As duas figuras à esquerda inclusive parecem fazer parte do mesmo corpo, tendo duas cabeças, devido à proximidade dos tons e da sutileza da insinuação do braço da que se encontra ao meio.

E no que elas pensam, o que observam? A pintura como um todo parece um convite à contemplação do espectador, mas por outro lado ela insere estas figuras ao centro da composição e atrapalha nossa contemplação completa; elas, por sua vez também observam e, como não vemos suas faces, nos colocamos no seu lugar e nos sentamos às rochas e observamos a natureza: o céu que praticamente nos engole, o mar que aparenta calmaria, mas nunca a possui, sendo sempre instável, a lua que entra para substituir o sol e mudar a tonalidade da atmosfera das cores. Somos pequenos perante tal paisagem, mas ao mesmo tempo desejamos entrar em harmonia com a natureza, tanto que nossas roupas se inserem no espaço, como dito anteriormente. Nosso pensamento flui e se movimenta incessantemente, não conseguimos nos movimentar devido à magnitude natural, tentamos nos conciliar espiritualmente com a natureza, mas talvez ao mesmo tempo tenhamos a (in)consciência de que isto não deve mais ser possível. Dessa perspectiva provém a melancolia dessa obra: uma tentativa, no campo da razão, de compreender, envolver e coroar pacificamente a natureza, assim como as elipses o fazem com a lua nascente. Utilizando as palavras do próprio artista, Caspar David Friedrich,

Tenho de me render ao mundo que me rodeia, unir-me às suas nuvens e pedras, para poder ser aquilo que sou. Preciso da solidão para poder comunicar com a natureza. (Friedrich, Caspar David in Wolf, Norbert, 2003, p. 1) 
Outra pintura (fig. 2). Duas figuras humanas no centro da composição e destacadas. Uma mulher e um homem. Ela tem as pernas delicadamente cruzadas, está recostada sobre o banco de madeira em que se encontra sentada, além de envolver a extremidade de um de seus braços com a mão direita fechada. Tem um biquíni preto e uma touca branca. O homem por sua vez, sentado ao seu lado e no mesmo banco, está curvado para frente. Não conseguimos observar suas pernas por inteiro, mas ele tem sua mão direita colocada para baixo, recostada sobre um de seus joelhos. Raios-de-sol incidem sobre as duas figuras que tem suas sombras projetadas sobre um dos lados da grande casa branca que ocupa metade do espaço pictórico. Esta está enquadrada de forma que algumas partes de seu telhado fogem do espaço da tela. Três janelas e uma porta. O tom de amarelo utilizado nas partes superiores da janela é repetido na parte esquerda da composição, em que quatro tecidos são movimentados pelo vento, dando uma harmonia para a construção da pintura. Destaca-se o vermelho de um desses tecidos e a escolha do pintor de, ao inserir o lado da casa central, misturar os tons negros relativos à sombra desta aos tons dos tecidos que voam.

Abaixo destes, um elemento que cria um diálogo diagonal dentro da pintura: dois pedaços de madeira que costumam ser utilizados para se prender barcos para que não escapem mar afora, geralmente vistos em portos e docas ou em cenas de praias como esta apresentada. Acontece que contrastando com as duas figuras centrais que estão sob o mesmo banco, mas que aparentemente sequer se comunicam, nem mesmo através de olhares, a corrente dessas madeiras as envolve e as prende. Elas não existem em separado, estão presas a si mesmas e não tem liberdade de movimentação. Lá ao fundo da composição, fincadas já nas rochas, temos mais duas dessas madeiras, só que em separado. Elas já não dependem uma da outra e tem um espaço considerável entre si. O mar mais atrás parece apenas rascunhado; parece uma piscina, não tem movimentação intensa e é de uma artificialidade notável. O céu é amplo e como que engole o espaço cedido ao mar. As duas fileiras de rochas contribuem com a idéia de profundidade da pintura, que convida o espectador a se perder na contemplação do céu adentro.

Estas figuras centrais contemplam o mar. Estão vestidas para adentrá-lo. Mas não o fizeram, estão secas. Além disso, a forma como se colocam sobre o banco, quase que entronizados por como o pintor as distribui em cima desse grande bloco de concreto, essa altura que os distancia da praia e também do mar, nos leva a crer uma atitude meramente observadora da natureza. São artificiais, parecem dois manequins. Ao mesmo tempo em que parecem contemplar o mar, pensamos sobre qual a relação entre estes dois indivíduos. Amantes, irmãos, amigos? Suas sombras no muro da casa parecem uma gravura, parecem afirmar que esse contato com a natureza não é possível, que eles estão presos a essa outra natureza, erguida pelo homem: a casa, as cidades, o mundo urbano que, neste momento histórico, já tomou o espaço da natureza com $\mathrm{N}$ maiúsculo. $\mathrm{O}$ momento de suspensão de uma perda: a perda da possibilidade de conciliação com a 
natureza. Já não é mais possível sequer tentá-la; o homem e sua tecnologia já chegaram a tal ponto que o espaço para a Natureza é pouco, inclusive o espaço para a comunicação e interação direta entre os homens. Não se trata mais de experiência entre o homem e natureza, mas sim de ciência. O homem está num lugar, a natureza está em outro. Este homem é tão individualizado que apenas centra seus pensamentos em si mesmo, ignorando todo o resto, todo o seu entorno: melancólico, finca raízes e reflexões em torno do eu; não consegue se mover por incapacidade de interação com qualquer coisa que não seja ele mesmo. Edward Hopper vai dizer que:

Meu objetivo na pintura sempre foi a mais exata transcrição possível das mais íntimas impressões da natureza. Se esse fim é inatingível, do mesmo, pode ser dito, é a perfeição em qualquer outro ideal da pintura ou em qualquer outra atividade do homem. ${ }^{47}$ (Hopper, Edward in Goodrich, Lloyd, 1993, p. 161).

Pensando a melancolia como um processo de perda, mas não uma perda objectual e consciente, mas sim já no campo da ideologia e da cultura e apresentando as obras acima como momentos de suspensão dessa relação entre homem e natureza, entre interior e exterior, é necessário contextualizar brevemente as obras de Caspar David Friedrich e Edward Hopper.

O primeiro, nascido em Greifswald no ano de 1774, falecido em 1840, é um dos expoentes do chamado romantismo alemão, que no campo da pintura também teve como representantes Philipp Otto Runge e Carl Gustav Carus. O século XIX é um momento da história da cultura em que o homem tenta de toda forma sistematizar o passado, além de perceber de forma potente o seu descolamento da natureza, se colocando efetivamente como centro do mundo física e mentalmente. A Revolução Industrial inicia seu alastro da Inglaterra para toda a Europa, em que nem mais os homens serão necessários, bastarão as máquinas. A obra de Friedrich, como as dos romantistas alemães em geral, tenta ir contra esse início do processo de homogeneização do homem que atingirá seu ápice justamente no momento da obra de Edward Hopper. Para tal é proposto um contato com a natureza, uma reconciliação, um retorno às origens. Quer-se a experiência, o fenômeno; se nega a ciência, o número. É o homem na natureza e a natureza no homem, tudo junto, uma coisa só. Uma união não apenas física, mas também e principalmente, espiritual. $\mathrm{O}$ homem se interioriza e projeta mentalmente esse reencontro com a natureza.

A própria produção de Friedrich não se encaixa nos estereótipos geralmente atribuídos aos românticos, vistos como se quisessem unicamente e de forma desordenada

47 "My aim in painting has always been the most exact transcription possible of my most intimate impressions of nature. If this end is unattainable, so, it can be said, is perfection in any other ideal of painting or in any other of man's activities". Tradução livre do autor. 
expressar sentimentos avassaladores. O pintor costumava entrar em contato com a natureza, pessoalmente, e depois ia ao seu ateliê onde, na mais profunda quietude, projetava mentalmente, disegnava suas paisagens ascensionais em que figuras humanas buscam essa integração com o que ainda há de natural na Terra. Contato do espírito Absoluto com o Sublime kantiano. Busca no outro, na natureza, de si mesmo. Uma natureza avassaladora, dominadora, que oprime os pequenos indíviduos das composições do pintor alemão. Hegel irá dizer que na arte romântica

\begin{abstract}
Mostram-se precários o repouso e a tranqüilidade que o espírito julgava ter encontrado na exteriorização corporal, e ele sente-se cada vez mais impelido a fechar-se em si mesmo, a procurar o repouso num acordo consigo mesmo. A aparentemente sólida e simples totalidade do ideal desagrega-se e cinde-se em duas: a do subjetivo em si e a da manifestação exterior, cisão que vai permitir ao espírito realizar uma pacificação mais profunda num mais íntimo acordo com o seu próprio domínio interior. O espírito que assenta no princípio da adequação a si mesmo, na fusão do seu conceito e da sua realidade, só no seu próprio mundo pode encontrar uma existência que concorde com a sua natureza, no seu mundo espiritual, na sua própria alma, na sua íntima sentimentalidade, em suma, na sua intrinsecidade mais íntima e mais profunda. Assim adquire o espírito a consciência de ter em si mesmo o seu 'outro', a sua existência enquanto espírito e de gozar a sua infinitude e a sua liberdade. (Hegel, Georg Wilhelm Friedrich, 1996, p. 570)
\end{abstract}

Friedrich ao olhar para fora irá buscar esse "repouso" que Hegel trata em seu texto. A paisagem, o olhar para o exterior num esforço de movimentar e encontrar o interior. Ele tenta contemplar, mas como suas figuras que estão ao meio da composição em seu Nascer da lua no mar, existe algum ruído, alguma coisa que não permite uma contemplação absoluta do Sublime. Como diria o próprio artista: "O que eu pretendia encontrar dentro da própria imagem, encontrei apenas entre mim próprio e a imagem". (Friedrich, Caspar David in Wolf, Norbert, 2003, p. 34)

Edward Hopper, americano, nascido em 1882 em Nova Iorque e falecido em 1967, se encontra num estágio da história da cultura que teve início justamente no século XIX de Friedrich. Já não há mais espaço para se pensar em uma Revolução Industrial; tudo já é indústria, tudo é fabricado por máquinas e os homens já são pré-fabricados, se acoplam a moldes de comportamentos ditados pela cultura de massa. Não se rascunha mais o conceito de indivíduo. Os humanos apenas conseguem focar em si mesmos, em suas vidas, suas trajetórias, suas opções, suas vontades. Há a necessidade do objeto, é preciso possuir, é preciso ostentar, é preciso demonstrar para todos seu lugar no mundo não mais pela existência em si, mas pela cultura objectual, criando quase que uma segunda 
natureza: uma natureza hominídea, erguida apenas por ele e que devora a natureza com que Friedrich tentava a reconciliação.

Não há mais espaço para a experiência. O homem está em um lugar, entronizado como as figuras de sua pintura acima analisada, Os observadores do mar e o que resta da natureza está em outro plano. A melancolia provém dessa solidão do homem. Já não há mais lugar para que ele consiga se recostar. Reconciliar-se não é possível nem mesmo no contato com o outro, que já não existe mais de forma sincera, pairando sobre todos a artificialidade, visível na construção dos corpos das figuras de Hopper, que mais parecem manequins, seja pela sua frieza física, seja pelos seus rostos meramente rascunhados e generalizantes.

... as intenções voltaram-se para o prazer proporcionado pelo conforto objetivando compensar a fadiga e aliviar a carga do trabalho. Mas o repouso também reduziu a sensibilidade do corpo, suspenso numa relação mais passiva com o ambiente e cada vez mais solitário. (Sennet, Richard, 2003, p. 305)

Dessas observações, as figuras de Hopper parecem se questionar em torno do que está por vir. São momentos de suspensão de uma existência humana que se questiona, mas não sabe porquê. O homem está numa vitrine e é mero objeto de observação, que no fundo nem chega a ser observado com nenhum grau de profundidade pelo outro. Existe por si só.

Pensemos brevemente nessas duas possíveis leituras da melancolia em outras obras de Hopper e Friedrich. A janela, metáfora proposta por Alberti para a pintura e símbolo da observação do outro, do que está no exterior, aparece em Mulher à janela (fig. 3) e Manhã em Cape Cod (fig. 4). Mas se no primeiro está presente a tentativa de conciliação entre a observadora, cuja roupa se integra ao interior da casa, e a janela que indica um pouco da paisagem exterior com barcos, em Hopper a janela é quase que como um espelho. Sequer conseguimos perceber se ela está aberta ou não, e a casa mais uma vez aparece devorando o espaço reservado à artificial natureza esboçada. Em Friedrich ainda há a possibilidade de se escapar pela janela e se vivenciar a natureza; em Hopper a figura está trancada dentro de sua casa e de sua artificialidade.

Numa referência mais direta à simbologia da melancolia, duas obras intituladas Meio-dia (fig. 5 e 6), a hora do demônio, as doze horas da expulsão de Adão e Eva, o início do declínio da luz da manhã, o momento sem sombras; a figura de Hopper permanece inserida em sua casa, não consegue se colocar na natureza, se encontra um degrau acima dela e apenas permite a entrada dos raios-de-sol pela abertura sutil de seu vestido. Já Friedrich coloca a pequeneza de seu homem no meio da natureza, numa tentativa da 
experiência de um com o outro, assim como em O monge à beira-mar (fig. 7), em que a figura se depara com o Sublime se desdobrando à sua frente, a infinitude buscada em si mesmo projetada no exterior. Enquanto isso, em Anoitecer em Cape Cod (fig. 8) as figuras humanas estão no limite entre a natureza hominídea e a Natureza, mas não conseguem se integrar quando juntos a esta segunda. Seus olhares não se encontram, estão focadas em seus mundos internos, em seu individualismo gritante. O homem talvez esteja tentando chamar a atenção do cachorro que por sua vez também não se integra a seus donos.

Uma melancolia baseada numa perda ideológica. Friedrich e a melancolia na tentativa de se reconciliar com a natureza, fazer o espírito Absoluto entrar em experiência com o Sublime da Natureza, através de um processo de idealização da mesma. Hopper e a melancolia de se ter atingido um estágio em que não é mais possível essa reconciliação, nem mesmo do homem com o homem, cada vez mais industrializado, frio e individualista - o homem pós-moderno que dá seus primeiros sinais no século XIX. Concluindo, propomos uma relação dessas duas leituras da melancolia com a talvez mais conhecida obra que também a problematiza, a Melencolia I (fig. 9), de Dürer. Panofsky em seu "Saturno e a melancolia" afirma que a figura da gravura está situada iconograficamente entre a imagem medieval do geômetra e seus aparelhos que visam tentar medir o mundo, e a figura do deus Saturno com seus elementos provindos da natureza. Podemos trazer isso para as poéticas de Hopper e Friedrich. Este se relaciona a Dürer nesse contato com a natureza, buscando a si mesmo e iconograficamente pela sua constante representação do mar com barcos; o outro nessa melancolia de um momento em que o homem de todas as formas possíveis e imagináveis já conseguiu medir o mundo e está rodeado de suas construções e abandonado a si mesmo. Com tons quase proféticos, Hopper, sempre mais interessado pela tradição da pintura do que pela abstração, tem uma frase em que toca justamente nessa questão homem e natureza, e com a qual termino este texto: "A pintura terá de lidarmais completamente e menos obliquamente com a vida e o fenômeno da natureza antes de se tornar ótima novamente" ${ }^{88}$ (Hopper, Edward in Goodrich, Lloyd, 1993, p. 164).

\section{Referências bibliográficas}

ANDRADE, Ricardo. Arte e ascese em Caspar David Friedrich. In: Revista Gávea no 12. Rio de Janeiro: 1994.

48 "Painting will have to deal more fully and less obliquely with life and nature's phenomena before it can again become great". Tradução livre do autor. 
CLAIR, Jean (Org.). Mélancolie - génie et folie en Occient. Paris: Gallimard, 2005.

GOODRICH, Lloyd. Edward Hopper. H. Nova Iorque: H. N. Abrams, 1993.

HEGEL, Georg Wilhelm Friedrich. O belo na arte. São Paulo: Martins Fontes, 1996.

KRANZFELDER, Ivo. Edward Hopper, Lisboa: Taschen, 2006.

KLIBANSKY, PANOFSKY e SAXL. Saturno y la melancolia. Madri : Allianza Editorial, 1991.

SALA, Charles. Caspar David Friedrich et la peinture romantique. Paris : Terrail, 1993.

SCHELLING, Friedrich Wilhelm Joseph. Filosofia da arte. São Paulo: Edusp, 2002.

SCHMIED, Wieland. Edward Hopper: portraits of America. Munique: Prestel, 1995.

SENNET, Richard. Corpo e pedra: o corpo e a cidade na civilização ocidental. Rio de Janeiro: Editora Record, 2003.

WOLF, Norbert. Caspar David Friedrich. Lisboa: Taschen, 2003. 


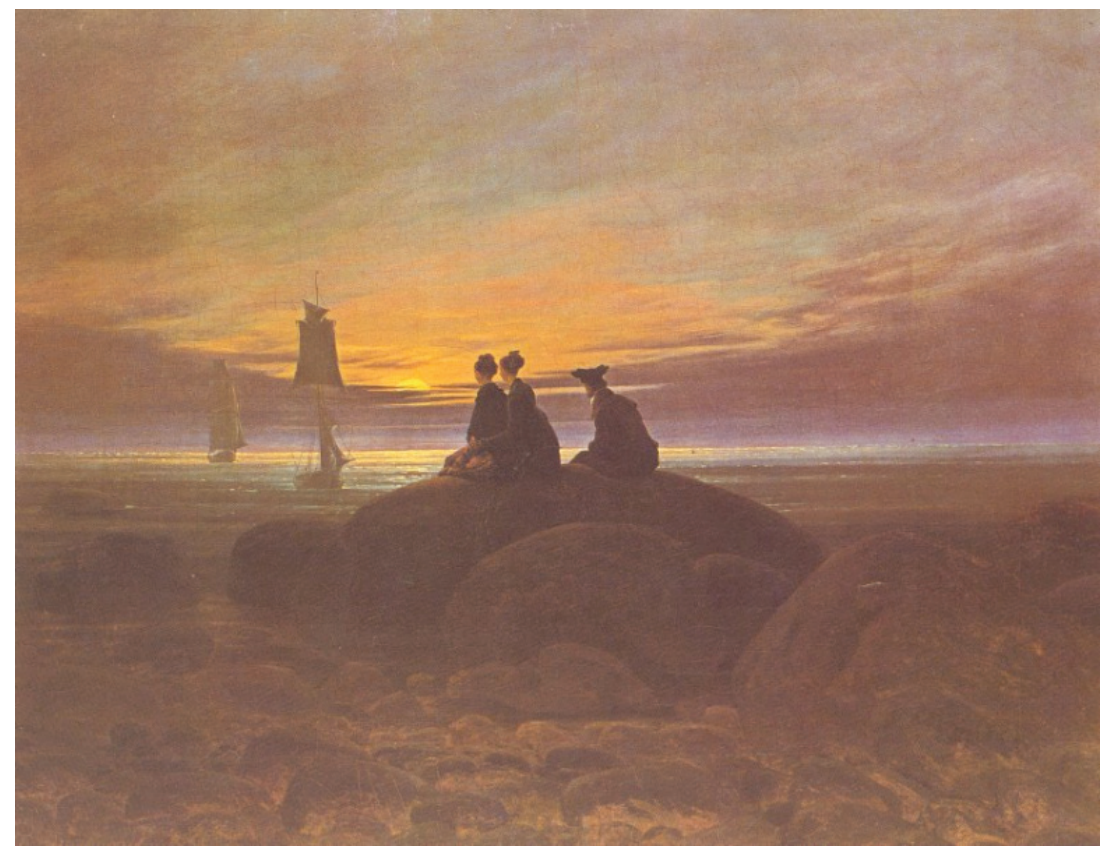

Fig. 1.

Caspar David Friedrich. Nascer da lua no mar. 1822, 55x71cm. Fonte: WOLF, 2003.

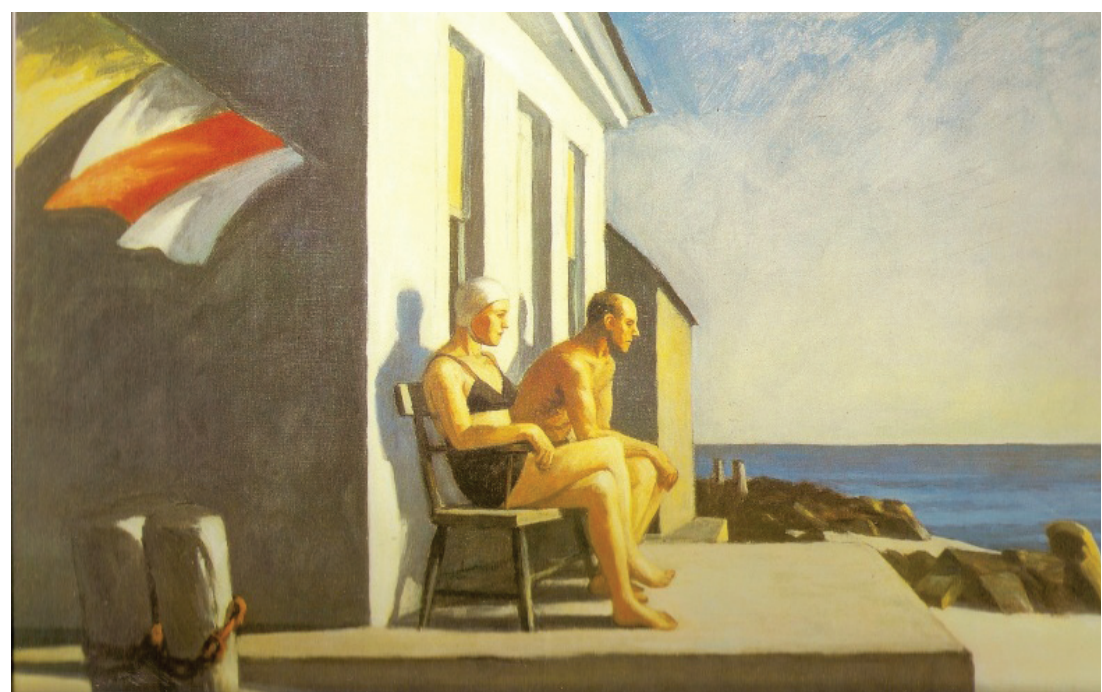

Fig. 2.

Edward Hopper.

Observadores do mar.

1952, 76x101cm. Fonte: GOODRICH, 1993. 


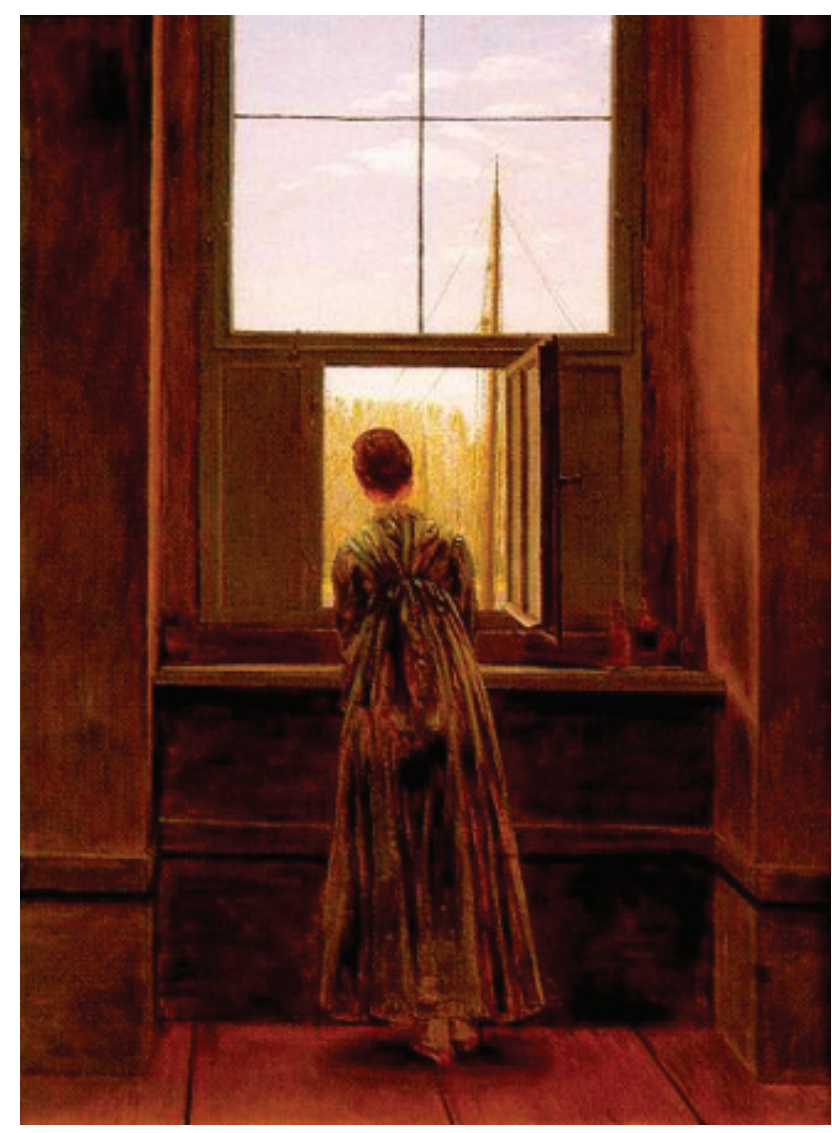

Fig. 3.

Caspar David Friedrich.

Mulher à janela.

$1822,44 \times 37 \mathrm{~cm}$.

Fonte:WOLF, 2003.

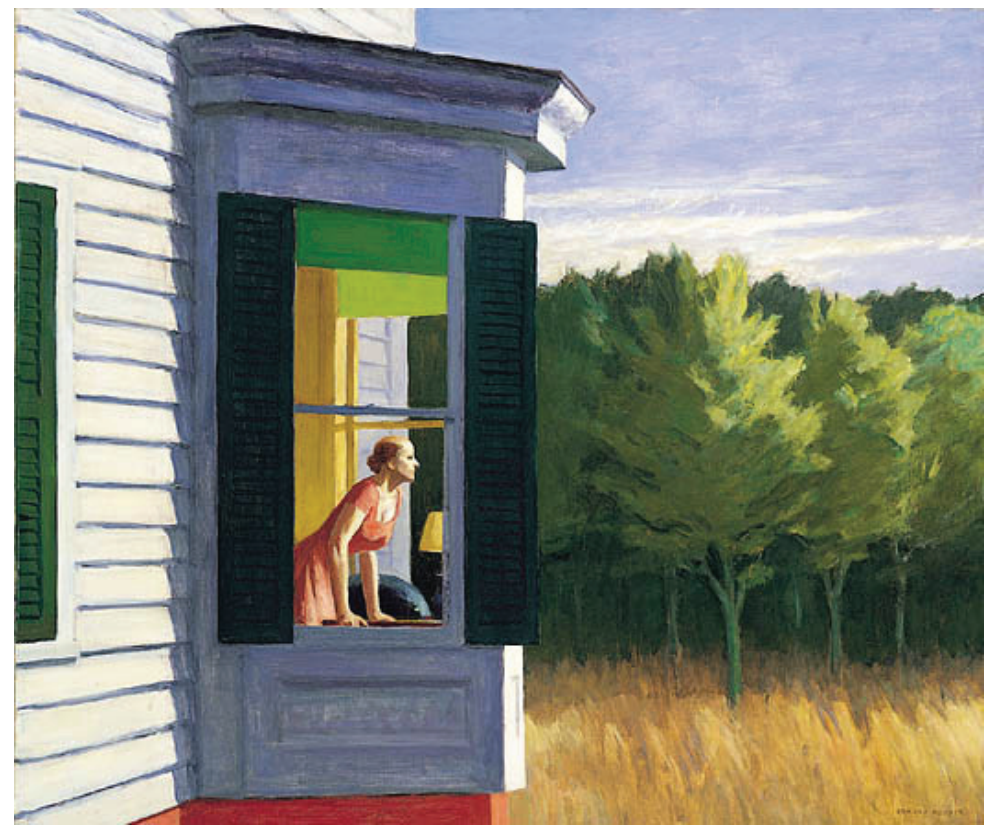

Fig. 4.

Edward Hopper. Manhã em Cape Cod.

1950, 87x101cm.

Fonte: KRANZFELDER,

2006. 


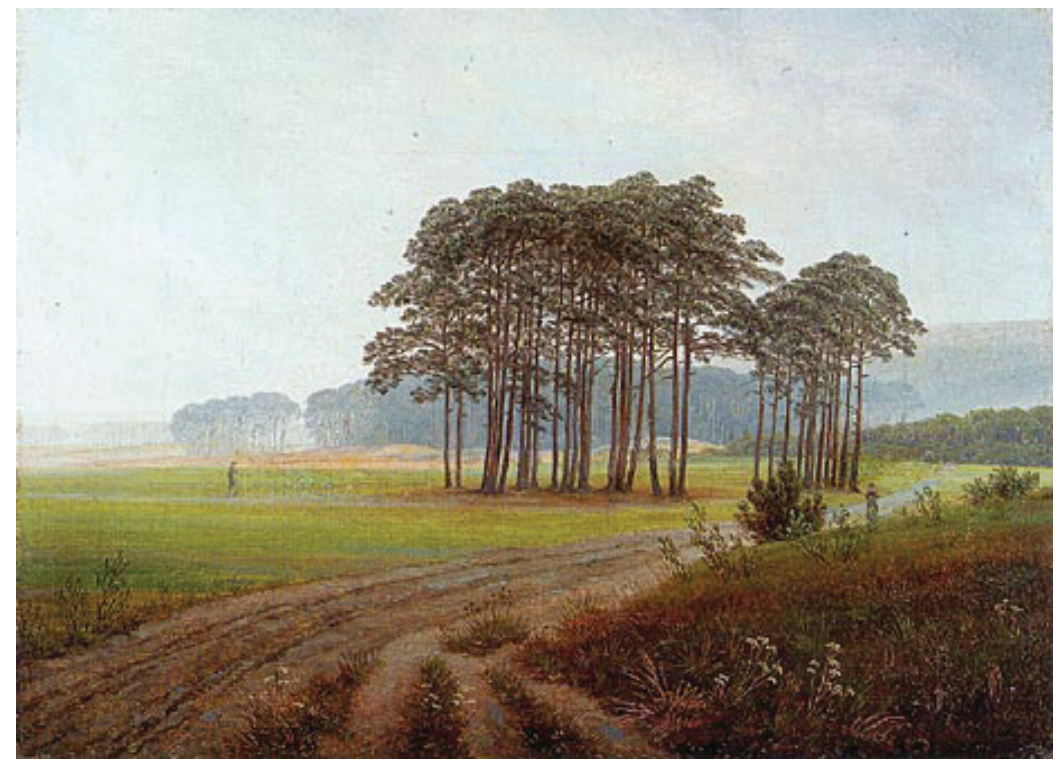

Fig. 5.

Caspar David Friedrich.

Meio-dia. 1822,

$22 \times 30 \mathrm{~cm}$.

Fonte:WOLF, 2003.

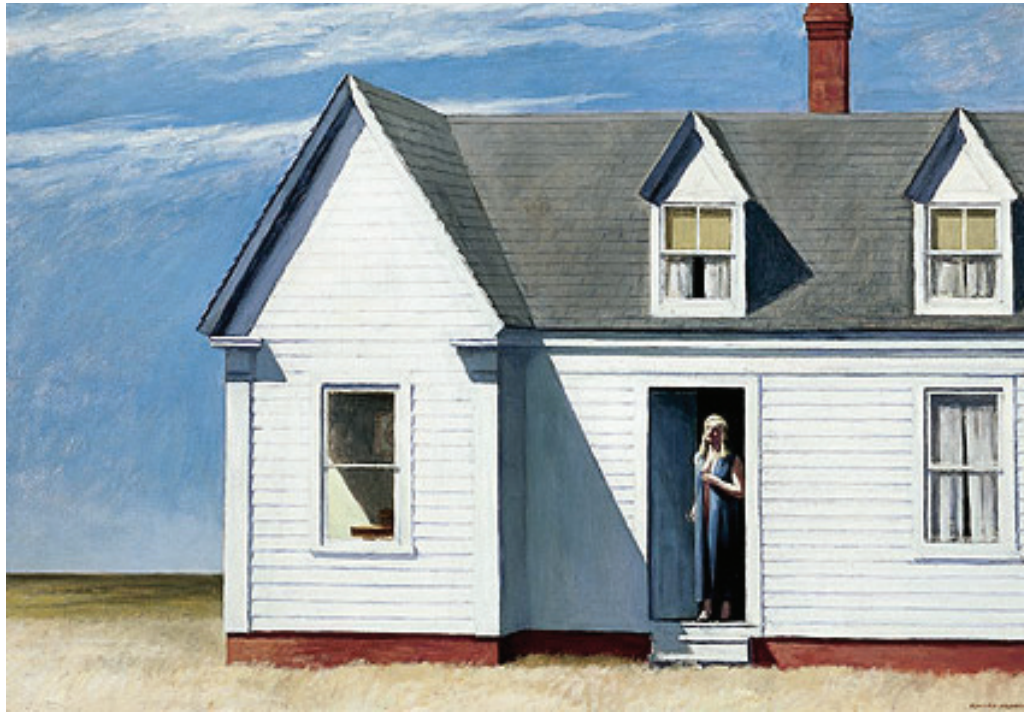

Fig. 6.

Edward Hopper.

Meio-dia. 1949,

$70 \times 100 \mathrm{~cm}$.

Fonte: KRANZFELDER, 2006.

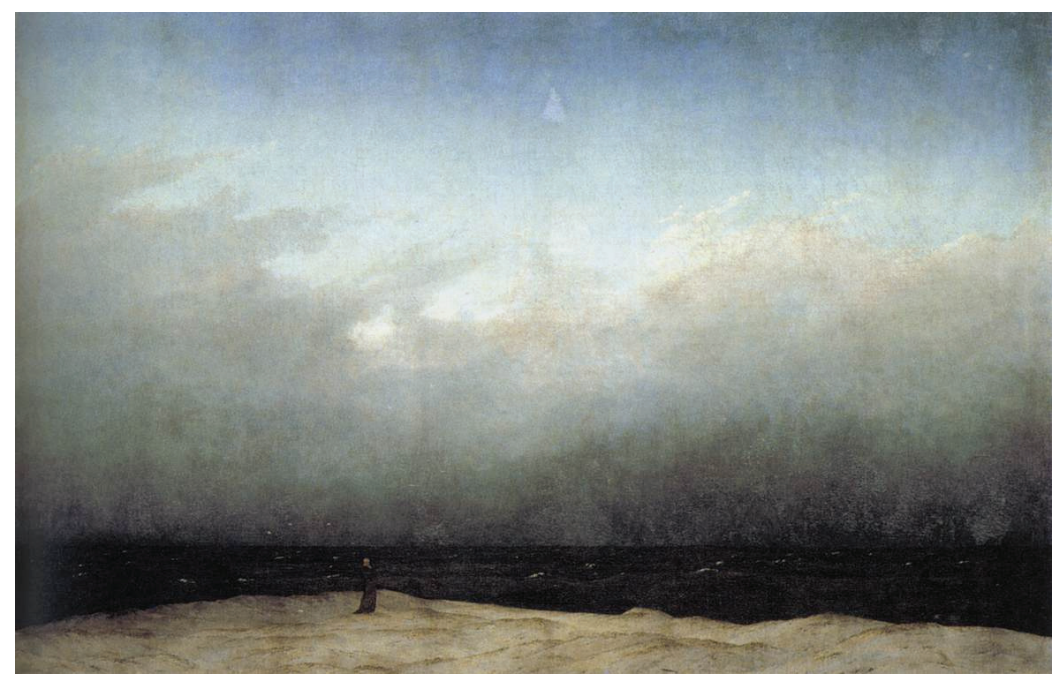

Fig. 7.

Caspar David Friedrich.

O monge à beira

mar.

1808-10, $110 \times 171 \mathrm{~cm}$.

Fonte: WOLF, 2003. 


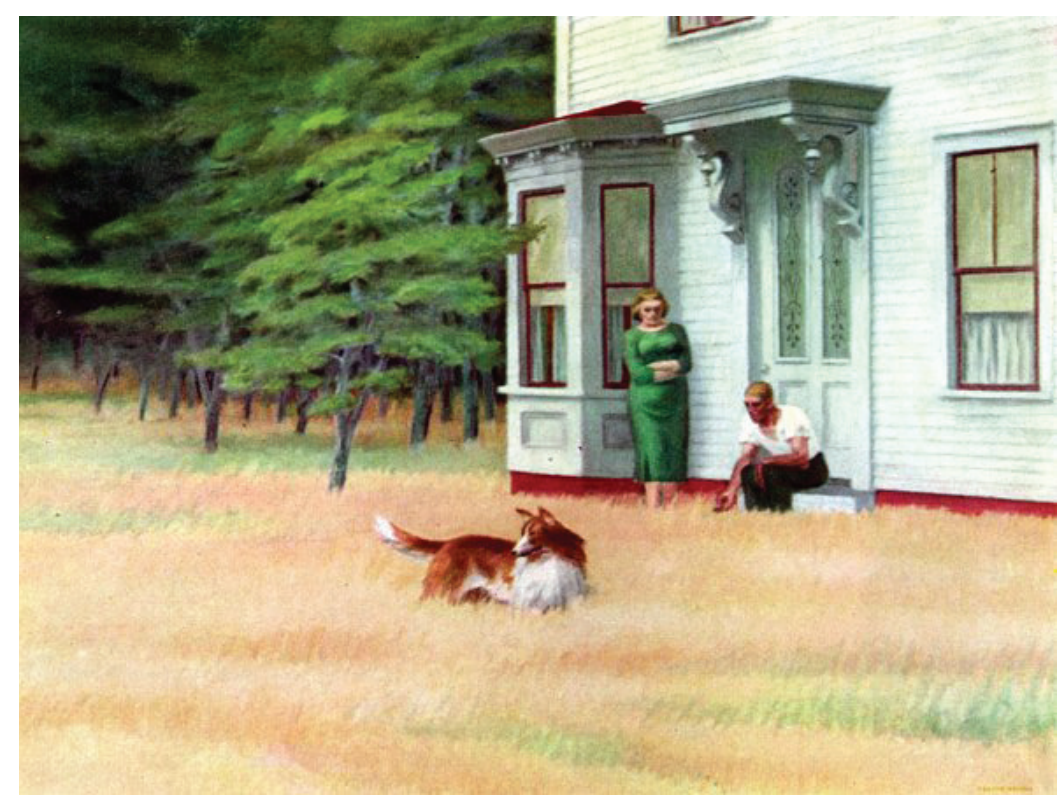

Fig. 7.

Caspar David Friedrich.

O monge à beira

mar.

1808-10, 110x171cm

Fonte:WOLF, 2003.

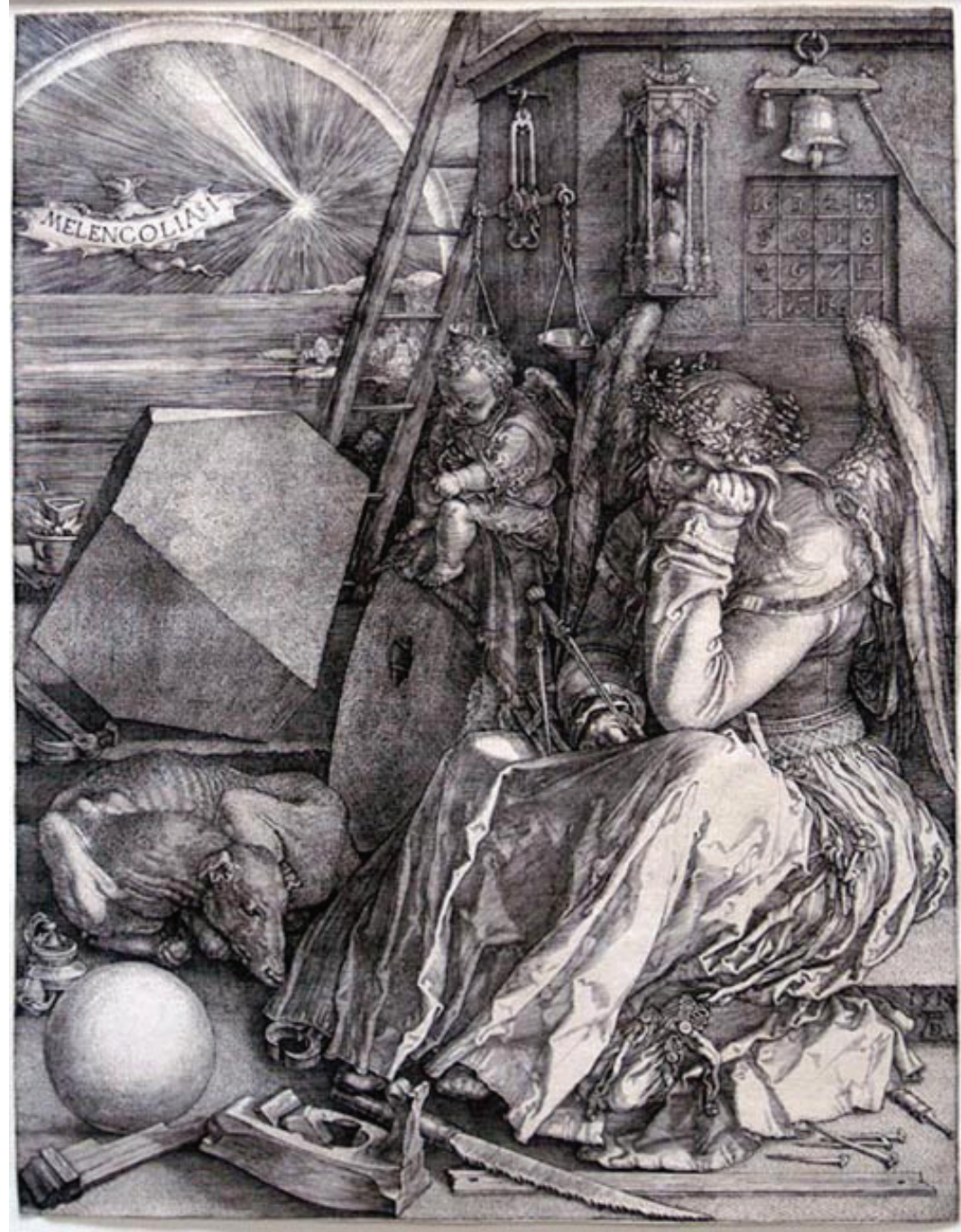

Fig. 9.

Albrecht Dürer.

Melencolia I. 1514,

$31 \times 26 \mathrm{~cm}$. 